\section{Superb image quality across the board}

If you provide many different types of treatment, you need an imaging solution that offers predictable, high-quality results across multiple modalities.

The CS 8200 from Carestream Dental is the system you're looking for.

Not only does this affordable, compact system offer a range of $2 \mathrm{D}$ and $3 \mathrm{D}$ imaging options, but the premium imaging functionalities and software ensure only the clearest results. This helps to ensure that you require fewer retakes and can accurately move forward no matter the challenge in front of you.

To find out more contact Carestream Dental on 08001699692 or visit www. carestreamdental.co.uk.
For all of your waste disposal and infection control needs

Initial Medical is an expert in waste segregation and disposal, as well as infection control. It offers various products, services and support to help every dental practice ensure the safety of staff and patients alike.

Whether you need the appropriately colour-coded waste bags, bins or sharps containers, a practice audit, a reliable waste collection service or clinically proven disinfectant and cleaning products, Initial Medical can help! We are even one of the few UK companies to now offer a safe collection and disposal service for lateral flow testing waste.

For information on the solutions available, or for expert advice and guidance to optimise your waste disposal and/or infection control, visit initial. co.uk/medical or call 08708504045 . js-davis.co.uk, calling 01438747344 or emailing jsdsales@js-davis.co.uk.

will extract root and root fragments in a controlled manner, in cases when conventional drawing should be avoided. Other features include:

$\rightarrow$ A newly developed quadrant, for the optimal supporting surface

$\rightarrow$ An innovative design, to reduce damage to bone and tissue

$\rightarrow$ Ideal as part of a protocol prior to immediate implantation.

Also from Meisinger is the Master-PinControl for the fixation of resorbable, nonresorbable and titanium membranes. Like the Benex-Control Professional, it offers safe, convenient use.
Meisinger tools are available from J\&S Davis, the supplier of quality dental

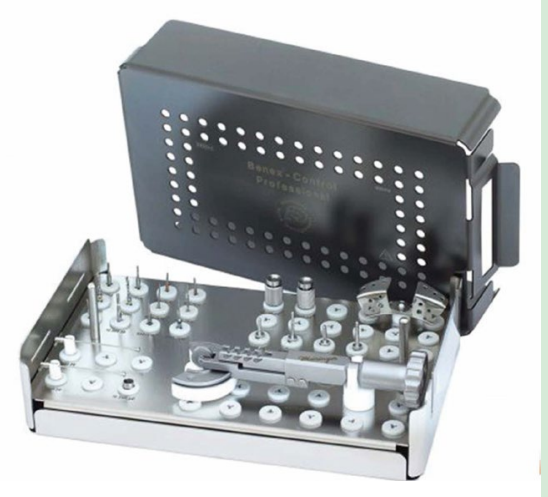

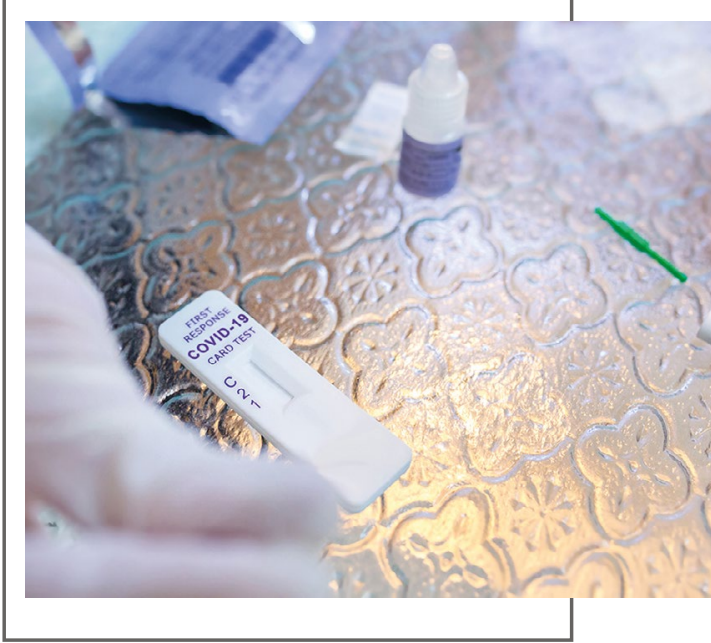

\title{
New partnership heralds easier endodontics for GDPS
}

Are you looking for files that put you firmly in control of endodontic treatment? Then look no further!

Now available exclusively through Wright Dental, Endoperfection's VaryFlex files offer amazing value without compromising on quality and are simple to use.
For example, the files have incredible flexibility due to the heat-treated nickeltitanium (NiTi) alloy and an $11 \mathrm{~mm}$ shank, which is shorter than usual, making working with VaryFlex very comfortable and easy.

For further information, please visit www.wright-cottrell.co.uk/ new-endoperfection-files-range/

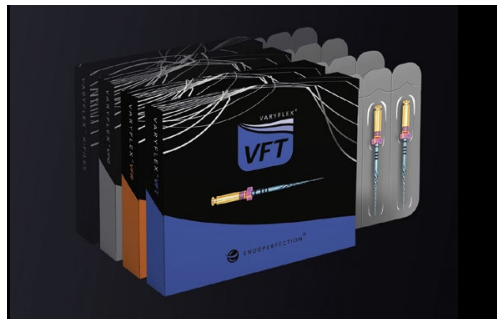

